\title{
ROTATING LIQUID BLANKET WITH NO FIRST WALL FOR FUSION REACTORS:
}

\author{
Ralph W. Moir \\ Lawrence Ljvermore Kational Laboratory \\ Liniversity of California \\ Livermore, CA 94550 \\ (415) 422.9808
}

\begin{abstract}
ABSTIACT
A sorojdal voriex of liquid FLiBe ( $\mathrm{LjF}+\mathrm{BeF}_{2}$ ) is suggested for the blayket of a fusion reactor. Because this reactor chamber has no solid first wall, it might avoid many of the problems that accompany conventional blanket design. The liquid blartiet is sustiined by nozzles that inject a con. tinuous layer of rool hyud on the inner surface. A second set of nozzles sends a stream of droplets across the diverted scrape-of laver or edge plisma to carty its heat away. The feasibility issues of most importance are judged to be avoiding utubulent hreakup of the vortex and preventing too much contamination of tre plasma by the evaporating FLiBe.
\end{abstract}

\section{INTRODUCTION}

Eliminating most if not all the solid material from a fusion reactor's first wall and support structure wou'd have enornous implications for fusion reactor development. This paper ronsiders replaring the first wall with a liquid blanket formed 1, rot at ing the hiud fast enough to overcome gravity. Flausible explarations for how such a scheme might work in

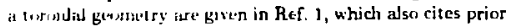
work on olher geonelries A possible working fluid might be the well-known molten sidt, $\mathrm{LiF}+\mathrm{BcF}_{2}$. The rotation is maint ained by nozzles that penetrate the moving layer of liq. uid. These nozzles are the only solid materials in the blanket. Since the nozzles would be replaceable, and the liquid acts as a shield, this blanket roncept virtually eliminates the need to develop long-lived malerials for the fusion envirnment

In linear or open-ended geometry, the two problems of gas and heat. removal from the leaking plasma have been worked out satisfactorily. However, in toroidal geometry, these two problems reman paramount, as even a slight failure to re. move heat and gas sufliciently can lead to excessive plasmn contamination. This paper iddresses these problems Re lated work that uses droplet jets or solid spheres to remove heat from the edget of fusion reactors is described in Fefs. 2 and 3

-This work was perfirered undef the auspices of the L.S. Eepart tnent of Energy by lawence litesmure Natianal Laboratory under Contract W. 74 id5. Enag. 4 b
The concept of a rolating liqud blanket is show'n in Fig. 1 One set of nozzles produces a droplet strcam that exposes a Jarge surfare area to the loaking plasma. This stfoars minjmizes the temraratue tise for a given heat flux, thus minimizing evaporation. A second set of nozzles lays a fresh, cool laver of salt over the hot layer of dropiets. The nozzles are closely spaced all the way around the torus in the toroidal direction. They are hydrodynamically shaped to minimize flow disturbances. Vencs are used to reduce turbulence that could bring hot fluid up to the fromt surface and cause excessive evaporation. The nozzles could be made of graphite, berylliurn, tungsten or certain other materials, possibly even stecl.

\section{Siart-up of Vortex or Rotation}

The sortex shown in Fig. J can be thought of as a portion of a Hill's vortex and cas have an elliptiral cross section if desired. To start the vortex flow, we close of the beam and pellet tube and fill the chamber with FliBe, which is punned to the inlet nozzles and removed from the outlet nozzles. These nozzles establish the vortex motion and sustain it against viscous drag on the penetrations and back wall. With the removal of a portion of the FliBe, the vortex opens a void in the center at the desired location. The access tubes and two sets of inlet nozzles then penetrate into this void, as st jwn in Fig. 1, and the access tubes can be drained. The plasma discharge can now be produced repetitively or continuously, independent of the vartex motion.

The above deseription may be flawed. For example, it is by no means clear that the vortex will present a smooth iruer surface facing the plasma and not be violenty turbulent, resulting in hopelessly contamining the plasma with evaporated $\mathrm{FLiBe}$. There is hope, however, that the optimistic picture may be completely realizable, and it is worth serious examination as a means of overcoming the many uncertainties and problems of more conventional blankel designs.

\section{Droplel Heat-Remoul ('apabiliț.}

We introduce some of the issues by presenting a calculation of heat removal ly druplets. Mary simplifying assumptions are included. We assime that the nozzles produce 


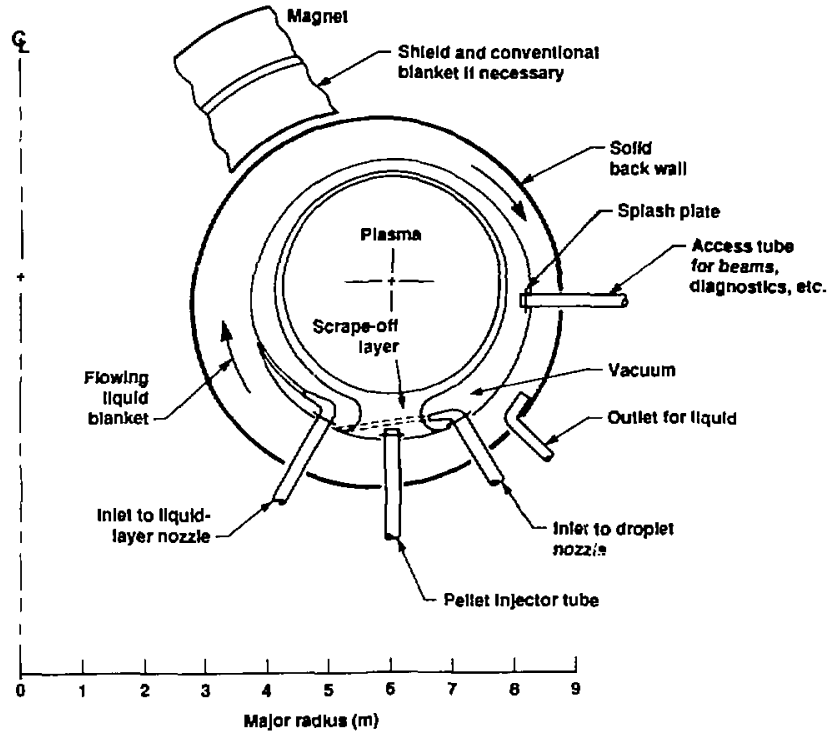

Fig. 1. Schematic of rotating lieud blanket with no solid first wall.

droplets of radius $r_{0}$ and speed $\nu_{0}$ injected across an edge plasms of path length $l_{0}$ For simplicity, we assume that the plasmis depasits heal uniformly over the entire droplet surface. This heat load is denoted as qo. The droplet surface temperat ure is given by the solution to the well-know'n heat conduetion equation (sce. fur example, Hef, 4).

The thermal diftusivity is $k / \rho c$, which for FLiBe is $1.7 \times$

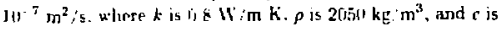
$2350 \mathrm{~J}: \mathrm{kg} k$ The thermal diftusivity Inne is

$$
\because=r_{0}^{2} \rho c ; k \text {. }
$$

The surfare ten:perist ure $T$ equals the temperature at the druplet center $T_{1}$ at zero ime and increases wich ume The cuantity ( $T$ T $\left.T_{B}\right)$ k garo ts given in Rief. 4 as a function of the dimensionle'ss tame

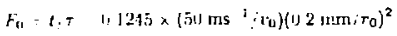

Figlere 2 sheses the heat absention for several droplet speeds is droplet suze, where ihe temperatise nse is $3100 \mathbf{K}$ and path

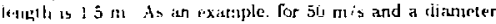

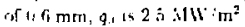

The arta is a cul itcross the edge plinms in relatuco ir,

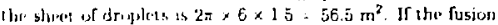

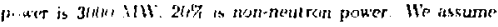

that half of this $20 \%$ is converted to $300 \mathrm{MIX}$ of penetrating radiation (bremsstrahiung, $x \cdot y$ ays, syncheotron ${ }^{1}$ and optcal), leaving $10 \%$ (300 MW) as nonpenctrating hwal on the inside surface. Or this we assume that 2-11 .11W goes to the flowing edge plasma and $60 \mathrm{MW}$ is distributed over the licuid first wall, giving $0.1 \mathrm{NW} / \mathrm{m}^{2}$ over the $474 \mathrm{~m}^{2}$ of liquid first wall. The surface temperacure increase is calculated from the Lquation, $\Delta T-2 q 0(1 / \pi k \rho c)^{5 / 2}$. Al a surface liyuid speed of $25 \mathrm{~m} / \mathrm{s}$, the FLiBe will increase in 1 cmperalure $b 20^{\circ} \mathrm{C}$ in one revolution. i.e., by the time the fresh cosl hquid covers the hrated-up surface. The $240 \mathrm{MM}$ is spread over $56.5 \mathrm{~m}^{2}$, giving an average power luading of $2 \mathrm{M14}: \mathrm{m}^{2}$ on the droplet slient.

Internal corculation inereases the efferivive renductivity of the drciplet 5 This might give three tmes the heal-jo ad rapahilut Oscillations of tha druplet are predicted lo fur. ther incrense conducturey bs a smilas fa: 1. o 6 Alse the

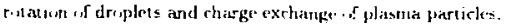
guring a meutral part icte heat Irad, will tord to disiributc the hout lead cover the tot do droplet surfase. that is, the tict ad

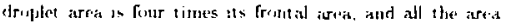

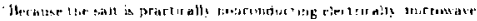

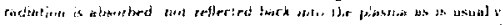

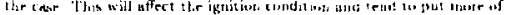

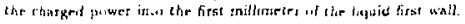




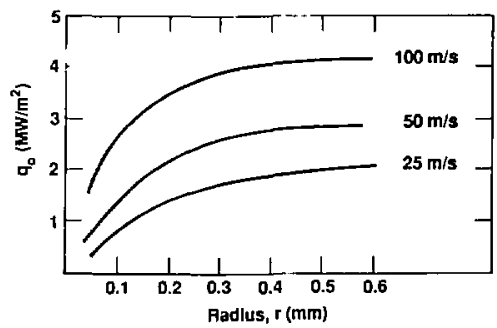

Fig. 2. I'niform heat load on a droplet vs droplet speed. This heat load is indicatse of the heat-removal capability of a thick droplel st reatn or sheet.

ts heated. These two efferts might inrease the heat-load capabilily by wel over a factor of 10 . Our example of go of $2.5 \mathrm{M} 111 / \mathrm{m}^{2}$ translates into an average heat flux on the drupless' exprosed sur race of about $90 \mathrm{MW} / \mathrm{m}^{2}$.

The plasma parurles E'-ike the droplel sheet at an acute angle beciaust thes fellow the magnetic field lines, which are mostly into the paper (toruidal direction) and only slightly in the plane of the figurs (poloidal direction). (The droplet sheec ran be seen in Fig. 1. as dashed lines.) The power density would be cnhanced by the inverse sine of this aciate angle ifl relat ion to ind !vidual druplets over the average power density on the sheet This might enlance the heal laad on the droplets by an order of magnitude. That is, the $4.2 \mathrm{NDW} / \mathrm{m}^{2}$ nugbt be enhanced $1 \mathrm{c}$ al sout $42 \mathrm{MW} / \mathrm{m}^{2}$, thus just matching the heat-removal capability. The heat-removal capability of droplets must be calrulated mor carefully in future work with as conphasis on minimizing evaporation, which means ketping the temperat ure rise at the droplet surface low.

Fur droplet heal removal la be efficient, the kinetic power carried by all the-drupplets (a large part of the pumping power) tnust be a small frartwon of the thennal power picked up 2 . This rat w is propistional to ro $u_{0}^{3} / g_{0}$, which requires that the lall mis driplets should be krgl under $1 \mathrm{~min}$ in diameter. For spetrds less than $100 \mathrm{~m} / \mathrm{s}$, the droplets can be much larger $\left(r_{n} \propto q_{0} ; \mathrm{t}_{0}^{3}\right)$

Incisentaily, the platma will charge the droplets negatevelv l. a fitw limes the eleelron Iemperatuse The effects of

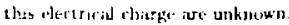

\section{Hapheratute of tilibe.}

Tllo- (vipuratiut of the liquid produces a vapor of $\mathrm{LiF}$ and $\mathrm{H}_{1}+\mathrm{F}_{2}$ (plus soma $\mathrm{l}_{1} \mathrm{~F}_{2}$ ) that will strike the edge plasma, where it will he lintized. Must of the $\mathrm{Li}, \mathrm{Be}$, and $\mathrm{F}$ juns will he returnad in the liquid, hus sume will enter the hot plasima regican arad there dilute the fusson fuel and produee radiattun One cist make reusonably accurate estimates of the evagesation rate aud therefore of the rate of arrival of this vapor al the colge plistra. One can also mstimate tho tolerable level of $L_{1}$, Be, and $F$ ions in the hot plasma. It is much more difficult to predict the fraction of incident ions on the edge plasma that penet rates into the hot plasma and the lifelime of these ions in the loot plasma. These difficult colculations are suggested for future work

The rapor pressure of FLiBe for the $47 \% \mathrm{LjF}-53 \% \mathrm{BeF}_{2}$ mixture is given by $\{1\}$

$$
\log _{10} P(\text { Torr })=9,401 \mathrm{i}-10,05 \mathrm{~d} / \mathrm{T}(\mathrm{k})
$$

Lsing an average molecular weight of 37 , the evaporation rate $J=m \bar{c} / 4$, and the evaporative cooling rate $Q$ (where the heat of vaporization of $49,000 \mathrm{cal} / \mathrm{g}$ mole is used), we get the values stion'n in Table 1 .

To illust rate the evaporation problem, we consider a case at $450^{\circ} \mathrm{C}$; however, ot hes temperat ures coming out of a transiet heat-transfer analysis should be ravried out. At $450^{\circ} \mathrm{C}$, $J=7.7 \times 10^{15} \mathrm{~cm}^{-2} \mathrm{~s}^{-1}$. The surface area of the first wall is $2 \pi 6 \times 2 \pi 2=473.7 \mathrm{~m}^{2}$, giving $3.65 \times 10^{22} \mathrm{FLiBe}$ molerules evaporated per sceond. This evaporation rate can be compared to the helium produrtion rate of $10^{21} / \mathrm{s}$ for $3000 \mathrm{MW}$ of fusion power. The plasma volume is $2 \pi 6 \pi 2^{2}=473.7 \mathrm{~m}^{3}$. Assuming that the impurity lifetime is 15 and that a fraction $f$ of the evaporating molecules penet rates into the hot plasma ( $1-f$ is the fraction swept out of the edge plasma), then the impurity density is

$$
n_{\text {FLEe }}=f 3.65 \times 10^{22} / 474=7.7 \times 10^{19} f\left(\mathrm{~m}^{-3}\right) .
$$

The ratio of impurity to fuel ions is

$$
n_{\text {FLiBr }} / n_{D T}=7.7 \times 10^{19} f / 2 \times 10^{20}=0.38 f
$$

If the impurity concentration can be $10^{-3}$, then $f$ must be $<0.0026$. It seems at least possible that the edge plasma can expel or sweep out the ionized, evaporating FLiBe this thoroughly and that the plasma may not be swamped with impurities. There are lower-viscosity (less $\mathrm{BeF}_{2}$ ) salt mix. tures that have much lower vapor pressure than the mixture used here, but those mixtures also nust operate at higher temperatures. The evaporation from the droplet stream must be added to the above rate, atw sputtering must also be in cluded. THe impurity bretum and the ability of the edge plasma to sweep out ionized innuritic's are especially in need of more analysis, while th. simple calculations above shauld also be done much more thoroughy.

We have discussed the etaporation of molten salt, but the remotal of tritum, denlerium and heliurn is idso necossary

\begin{tabular}{|c|c|c|c|c|c|}
\hline$T\left({ }^{4} \mathrm{C}\right)$ & $T(\mathbf{K})$ & $P$ (Tors) & $n\left(\mathrm{~cm}^{-3}\right)$ & $J\left(\mathrm{~cm}^{-2},=1\right.$ & $Q\left(\mathrm{w}^{-5}\right)$ \\
\hline 400 & 673 & $2.9^{-1} \times 10^{-8}$ & $42 \times 10^{10}$ & $7.4 \times 10^{14}$ & $2.5 \times 10^{-5}$ \\
\hline 450 & 723 & $32 \times 10^{-6}$ & $4.2 \times 10^{11}$ & $77 \times 10^{16}$ & $2.6 \times 10^{-3}$ \\
\hline 500 & 773 & $2.5 \times$ & $31 \times 10^{12}$ & $5.9 \times 10^{10}$ & $2.0 \times 10^{-2}$ \\
\hline 550 & 823 & $10^{-3}$ & $1.8 \times 10^{13}$ & $3.5 \times 10^{17}$ & 0.12 \\
\hline 600 & 873 & $7 . B \times 10^{-3}$ & $8.6 \times 10^{13}$ & $1.7 \times 10^{16}$ & 0.58 \\
\hline
\end{tabular}
and will be left for fulure work

Table 1 Exaporation paranneters for FliBe. 

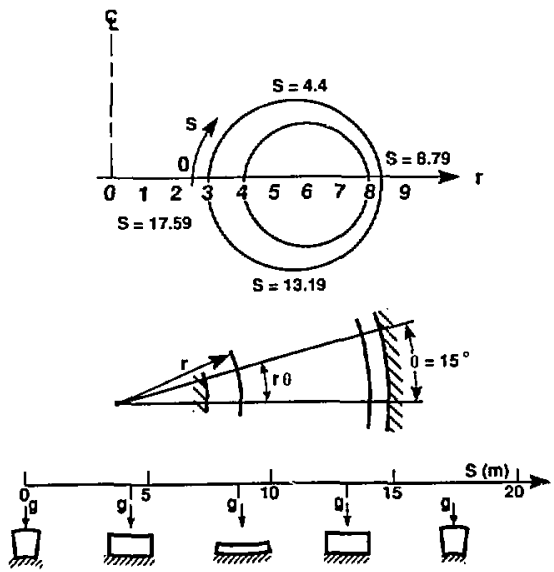

Fig. 3. Cross section of a fluid element as the clement is followed around the minor radius. The acceleratiun g is shown for vasious posilions is thir fluid element rotales around the circumference of the torus.

\section{Hydmdyamics of Hotating Laver}

Turbulence. Turbulence could break up the vortex. By break up we mean that edd) motion could bring hot FLiBe to the surface that is exposed to the plasma and contami. nate the plasma by its evaporation, whereas the craporation rate of the cool FLiRe might be tolerable. There are two main driving forees for the turbulence. First, the drag on the back wall and nozzles results in a shear in the flow. Second, the cross section of the flow varies as it rotates, as shown in Fig. 3. The layer on the outside is typically about halr as thick $(0.38 \mathrm{~m})$ as the layer on the inside $(0.84 \mathrm{~m})$.

For example the rotating speed rould vary from 10 to 50 $\mathrm{m} / \mathrm{s}$. The arceleration is $v^{2} / r$, so for a fir st-wall radius of $2 \mathrm{~m}$, the acceleration is 25 to $1250 \mathrm{~m} / \mathrm{s}^{2}$, or 2.55 to 127 times the acceleration due to gravily. (The acceleration due to gravity is $98 \mathrm{~m} / \mathrm{s}^{2}$ and is called I $\mathrm{g}$ ) The Reynold's number is given betes:

$$
N_{\text {Re }}=d i_{m} p / \mu \text {. }
$$

At $400^{\circ} \mathrm{C}$, rorresponding to the inlet temperature, the viscosity $\alpha$ is 4.65 J'a s; at $660^{\circ} \mathrm{C}$ it is 0.05 Pa.s. (For $45 \%$ LiF - $55 \% \mathrm{BeF}_{2}$. wither nixxtures with less $\mathrm{BeF}_{2}$ have much lower vacosities atud lowet mapor pressures.) The mean speed $v_{m}$ is taken to be apyroximately $15 \mathrm{~m} / \mathrm{s}$ (J1 g), and the density is $2650 \mathrm{~kg} / \mathrm{m}^{3}$. The fleynold's number varies from 28,000 to 370,000. These values are more thin an order of magnitude larger than the usual transition Feynold's number of af fe.w ibrussand. Parhays the hydraulir dianneter stould be less than the full a hirkness assumed above. The large 5 force might allow a latger Reynold's number for a given annount of turbulence. The magnetic ficld rught idso help in suppressing the turbulence. Using fow vanes or artificially producing a flow on the back wall with jets or moving surfaces might also help prevent turbulence or minimize the effect of liringing hat liquid to the free surface.

Splash Suppression. Ench tube penctrating through the moving layer must be designed to minimuze splashing. The fow of liquid past the tube is analogous to the movement through waier of the outboard mol or shavt on a speed boat. Because the speeds for the nowing liquidl and for speed berats are similar, the design of the tubes and shalt could be similar. The leading and trailing edges of the tube would be made sharp, like those of the housing on an outboard notor shaft, as shown in Fig. 4 . Splash plates as shown in Fig. 1 would also be used. A caleulation of the drag of the ligivd on the penctrating tubes and on the back wall should br made.

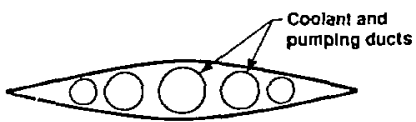

Fig 4 Cross section of a budrudynamically sesigned lube

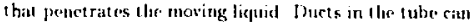
cerry cosolant and pump gas 


\section{POSSIBLE SOLUTION TO CONTAMINATION PROBLEM}

A potential solution to the problem of plasrua contamination by evaporating FliBe has been suggested [7]. It may be possible and prartical to replace the droplet nozzles on the end of the tubes that penctrate the flowing liquid with limiter or divertor plates. Such an alternative configuration is show'n schematically in Fig. 5. Almost all of the plasma power will hit the liniter plates and little will hit the liquid, thus gratly reducing the heat-removal requisements on the liquid and the evaporation problem. In addition, the tubes themselves car carry coolant to and from the structure and accommodate ducts to purnp gas as well (see Fig. 4).

\section{ELECTRICAL RESISTANCE IN TOROIDAL DIRECTION}

For a 6-m major radius, a 2-m first-wall minor radius and a 1-m-thick rotating layes, we get the following resistance:

$$
R=\rho \times l / A=0.038 \Omega,
$$

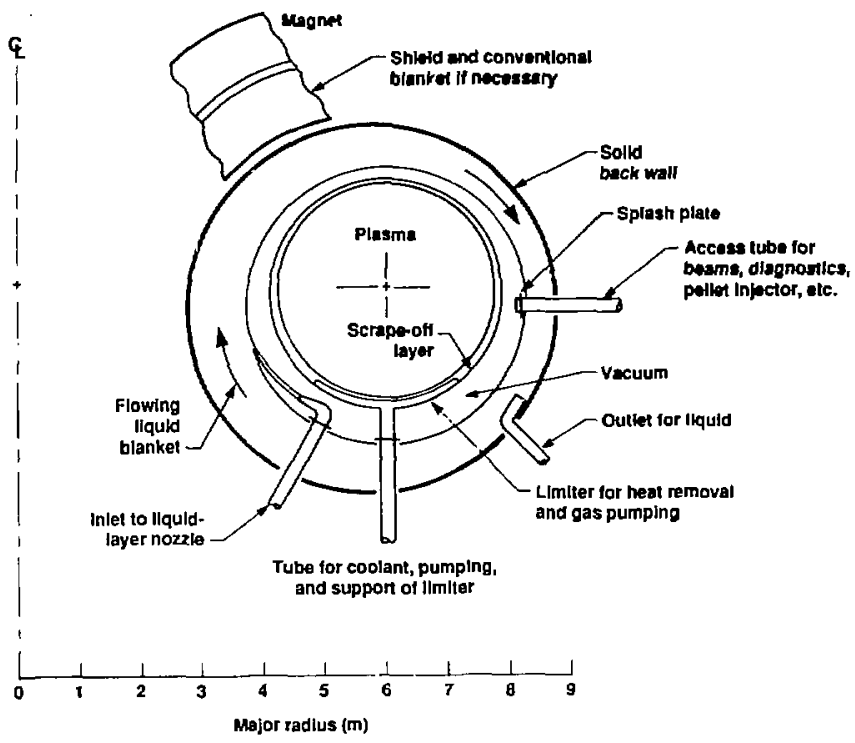

Fig. 5. As atl altemative configuration, limiter or divertor plates are nount red on the hydrotynamically shaped tubes penetrating the roiatiug liquid. Gas-pumping ducts ave incorporated into these tubes. The limiter plates replace the droplet-slicet heat-removal system of Fig. 1 .
This high resistance will result in negligible short circtuting of the induced toroidal current. Other liquids that have much lower resist ance and higher induced currents, sucl as bi lium, could have important hamful elTects.

\section{CONCLUSION}

The idea of eliminating the solid first wall of a fusion reactor and replacing it with a flowing or rotating liquid blan. ket is attractive because it prornises to eliminate many prob. lems faced by fusion reactor designers. This paper discusses the two most inportant feasibility issues: avoiding turbulent breakup of the vortex and preventing too much contarination of the plasma by the evaporating FLiBe. Both issues are judged to be serious but possibly summountable problems.

$$
\begin{aligned}
& A=\text { area }=1 \times 2 \times \pi \times 2.5=15 \mathrm{~m}^{2} \\
& t=2 \times \pi \times 6=36 \mathrm{~m}, \text { and } \\
& P=0.016 \Omega \mathrm{m} .
\end{aligned}
$$


Other issues are the lifetime of impurities, the allowed impurity concentiration, the fraction of evaporated FLiBe that penetrates into the hol plasma, the heat-removal capability of the droplets, and the effect of electrical charge on the droplets. Eliminating the first wall would be extremely beneficial; therefore, we welcome and encoluage further work to address the issucs discussed in this paper.

\section{ACKNOWLEDGMENT}

I thank Virgil Sclyrock for pointing out to me the impor. tance of juternal circulation in droplets.

\section{REFE:RENCES}

[1] R.W. MOIR, "Rotating liquid Blanket for a Torojda] Fusion Reactor," Fusion Engineering and Design 5269 (1987).

[2] W-S. Y'L, J.R. POWELL, J.A. FILLO, and J.L. USJER, "TRAIL-A Tokarnak Railgun Limiler," Fusion Technol. 6, 181 (1984).
[3] H.G. KARASEV, O.A. LIELAUSIS, E.V. MLRAV'EV and A.V. TAPANAEV, "liquid Metals in Fusion Reastors with Magnetic Confinement," Froc, of the Fourth Techniral Committee Meeting and Workshop, Yalt a, 26 May-6 Junc 1986, Fusion Reactor Design and Technolog. 1986, Vol. 2, International Atomic Energy Agency, Vienna 1987, 239-272

[4] H.S. CARSLAVY and J.C. JAEGER, Conduction of lleat In Solids, and Ed, (Oxford Press, London, 1959), p. 212.

[5; B. ABRANTON and W.A. SIRIGNANO, "Droplet Vaporization Model for Spray Combustion Calculations," presented at the session on Combustion Processes at the AlA A 26th Acrospace Scinnces Meeting, Reno, Nevada, January 1988.

[6] K. HIJKATA. Y. MOII, and 5. KAพYAGUCH1, "Direct Contact Condesisation of Vapor to Falling Cocled Droplets," Int. J. Hoat Mass Thnnsfer 27, 1631 (198.1).

[7: J.C. THOMLA, UC Davis Dept. of Applied Science, private comununication (September 1986). 